\title{
Acute hyperglycaemia in Cystic Fibrosis Related Diabetes: The role of insulin pumps
}

Samantha Drew, Rebecca Margetts, Hannah Gordon, Catherine Peters

Great Ormond Street Hospital for Children NHS Foundation Trust, London UK

\section{Background}

- Cystic Fibrosis Related Diabetes (CFRD) is the commonest comorbidity in CF leading to increased mortality rates

- CFRD is associated with reduced lung function and poor nutritional status

- The pathophysiology includes pancreatic fibrosis, reduction in acell and Bcell mass, delayed insulin secretion and variable insulin insensitivity. Insulin production can fluctuate with progression over time to an insulinopenic state ${ }^{1}$ (figure 1)

- Clinical condition may also influence insulin sensitivity, leading to hyperglycaemia in acute respiratory episodes ${ }^{2}$

Insulin is the recommended treatment for CFRD 2

- Continuous subcutaneous insulin infusion (CSII) is increasingly used in children and young people with type 1 diabetes but there are few publications on CSII use in those with CFRD

- CSII has the advantage of fewer injections which is an important factor for CF patients who already have a heavy burden with their complex treatment regimes ${ }^{3}$

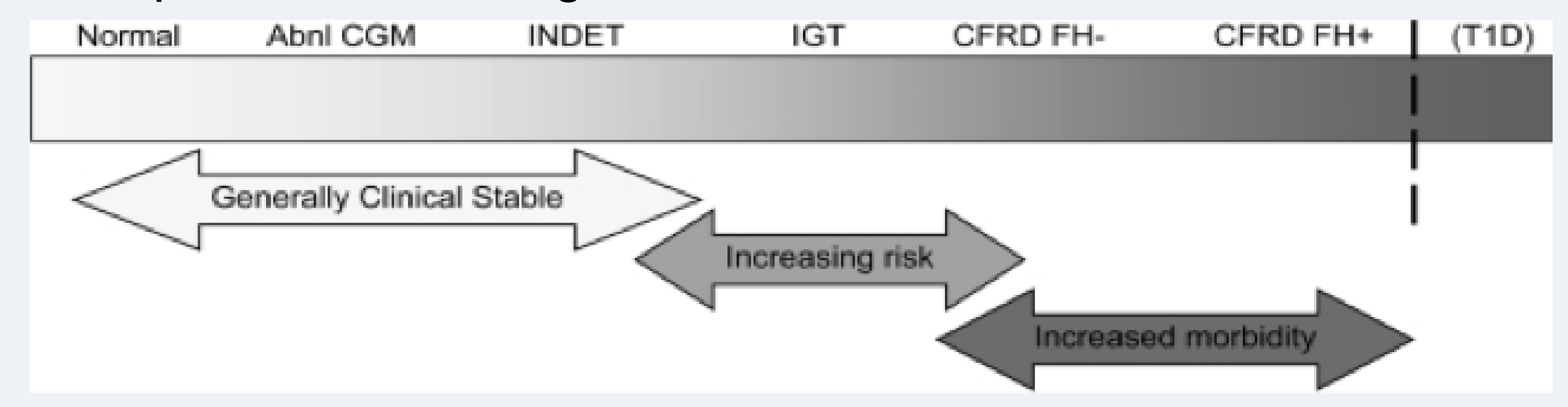

Figure 1 adapted from Moran $2010^{1}$

\section{Case 1}

15 year old female diagnosed with CFRD following positive OGTT and elevated HbA1c (7.1\%)

- Commenced on Insulin detemir injection once a day (4 units)

- Within 4 months she presented to her local A\&E with blood glucose $>20.0 \mathrm{mmol} / \mathrm{L}$, polyuria, polydipsia and negative ketones indicating an insulinopenic state. Discharged home

- Admitted to GOSH and commenced IV insulin, requiring $>2$ units/kg/day

- Treatment options offered multiple daily injections (MDI) and CSII, patient opted for CSII

- Commenced insulin pump therapy (1.4 units/kg/day)

- Highly motivated, positive parental support and excellent self management

\section{Case 2}

15 year old female diagnosed with CFRD following positive OGTT and elevated $\mathrm{HbA} 1 \mathrm{c}(6.5 \%)$

- Commenced on Insulin detemir injection once a day (2 units)

- Two years later presented to local A\&E with blood glucose $>20.0 \mathrm{mmol} / \mathrm{L}$, polyuria, polydipsia and negative ketones indicating an insulinopenic state. Discharged home

- Admitted to GOSH and commenced IV insulin, requiring $>2$ units/kg/day

- Commenced on MDI with carbohydrate counting (1.5 units/kg/day)

- Initial improvement in BG control was followed by issues with adherence to insulin injections, low mood and suicide attempt

- Three and a half years after diagnosis a decision was taken to support her request to start insulin pump therapy

- Commenced insulin pump therapy (0.74 units $/ \mathrm{kg} /$ day)

- Highly motivated in using pump therapy

- Overall engagement with CF MDT improved, however some ongoing non-compliance with CF treatment

\section{Outcomes}

- HbA1c improvement was seen at 6 months despite a reduction in insulin requirements

- The greatest improvement was seen in psychological wellbeing and subsequent engagement with all treatments

\begin{tabular}{|l|c|c|c|c|} 
& \multicolumn{2}{|c|}{ Case 1 } & \multicolumn{2}{c|}{ Case 2 } \\
\hline & Pump Start & 6 months & Pump Start & 6 months \\
\hline HbA1c & $8 \%$ & $7.70 \%$ & $14 \%$ & $8.60 \%$ \\
\hline $\begin{array}{l}\text { FEV1 } \\
\text { (\% pred.) }\end{array}$ & $1.72(56.3 \%)$ & $1.88(61.9 \%)$ & $2.08(63.6 \%)$ & $1.88(57 \%)$ \\
\hline BMI sds & 0.28 & 0.11 & -2.44 & -0.93 \\
\hline $\begin{array}{l}\text { Insulin } \\
\text { requirement } \\
\text { (units/kg/d) }\end{array}$ & 1.4 & 0.5 & 0.74 & 0.6 \\
\hline
\end{tabular}

\section{Case 1 comments}

"First of all I had injections, but I had to have so many of them that they just thought I should just go on an insulin pump instead"

"The pump makes me feel better...I think it's much better to be on the pump because now I don't have to have any injections"

\section{Case 2 comments}

"I take insulin with everything I eat, but I'm on an insulin pump so I don't have to do any injections"

"I type in my blood sugar level and then the number of carbs I'm eating then I press a button and it delivers the insulin...It makes me feel a lot better"

"The transformation was dramatic...she didn't have to think about insulin which had removed a great burden" (Clinical psychologist)

\section{Discussion}

- These cases show that young people with CFRD can present in an insulinopenic state requiring as much insulin as a young person with Type 1 diabetes

- Children and young people with CF require a high calorie diet, with multiple meals and snacks. Therefore multiple injections are required to achieve euglycaemia in $\mathrm{CFRD}^{4}$

- Limiting carbohydrate intake or omitting insulin can effect nutritional status and growth. An insulin pump gives the ability to give insulin without multiple injections ${ }^{4}$

- When managing CFRD the goal of treatment is not necessarily reduction in $\mathrm{HbA} 1 \mathrm{c}$ but supporting the young person to manage the burden of a second chronic disease

- In a cohort of patients with CFRD, insulin pump therapy has the potential to give these children and young people the best quality of life alongside improved glycaemic control

\section{REFERENCES}

Moran A, Becker D, Casella SJ et al. Epidemiology, pathophysiology, and prognostic implications of cystic fibrosis-related diabetes: a technical review. Diabetes Care 2010; 33: 2677-2683.

2. ISPAD Clinical Practice Consensus Guidelines 2014. Management of cystic fibrosis-related diabetes in children and adolescents. Moran A; Pillay K; Becker DJ; Acerini CL; International Society for Pediatric and Adolescent Diabetes. Pediatric Diabetes. 15 Suppl 20:65-76, 2014 Sep.

Sulli $\mathrm{N}$ et al. Use of continuous subcutaneous insulin infusion in patients with cystic fibrosis related diabetes: Three case reports. Journal of Cystic Fibrosis 6 (2007) 237-240

4. Hardin DS et al. Use of the insulin pump in treat cystic fibrosis related diabetes. Journal of Cystic Fibrosis 8 (2009) 174-178 